\title{
Problem Types and Open Innovation Governance Modes: A Project-level Empirical Exploration
}

\author{
By Mehdi Bagherzadeh, Andrei Gurca, and Sabine Brunswicker
}

\begin{abstract}
Irrefutable evidence shows that greater openness toward external partners enhances a firm's ability to solve innovation-related problems. To manage open innovation (OI) projects, firms use a variety of governance modes, including market-based contracts, platform intermediaries, and equity and non-equity partnerships. While innovation projects can be very diverse and characterized by various attributes, such as complexity and knowledge hiddenness, only a few conceptual studies have hitherto considered project attributes as drivers of OI governance mode selection. Using a sample of 85 OI projects and a set of illustrative cases, this paper explores empirically how project attributes influence OI governance mode selection. This empirical study advances previous conceptual work on OI governance. By accounting for project-level heterogeneity, we explore the micro-foundations of OI and provide more stable and fundamental insights into OI governance than previous industry- and firm-level analyses did. In addition, we suggest that effective OI management depends on matching project attributes with the benefits and costs of specific governance modes. Finally, we argue that this study enhances understanding and conceptualization of the relationship between project complexity and decomposability in the context of OI.
\end{abstract}

\section{MANAGERIAL RELEVANCE STATEMENT}

This study can help managers choose the appropriate governance mode for their OI projects by providing an empirically supported decision-making framework that accounts for the interplay between problem attributes and the costs and benefits of various OI governance modes. Our OI governance roadmap can in particular inform early stage decisions, which may have important implications for resource allocation during later stages of the project. Moreover, our findings can help managers decide whether to decompose complex problems into different sub-problems to which they can find solutions in collaboration with external partners. Our findings 
show that such decomposition does not only depend on problem complexity. Instead, problem complexity and knowledge hiddenness jointly drive problem decomposition decisions. More precisely, managers can think of complex problem decomposition only when the knowledge required for sub-problem solving exist, and they know which partners have the knowledge required to help them with their innovation projects. 


\section{INTRODUCTION}

Open innovation (OI, hereafter) is becoming inescapable in large firms, who are increasing their investments of both financial and managerial resources in OI activities [1-3]. A recent study of large firms in the USA and Europe reports that OI is the prominent innovation mechanism adopted by large firms, with $78 \%$ of surveyed firms adopting OI, and financial support for OI increasing for 61\% of OI adopters [4]. To leverage the knowledge of external partners, firms can use a variety of OI governance modes (OI modes, hereafter), such as market-based contracts (e.g., licensing agreements), OI platforms (e.g., intermediaries), non-equity partnerships (e.g., alliances), and equity partnerships (e.g., joint ventures) $[1,5,6]$. While current evidence suggests that firms are increasingly shifting from closed to open innovation, it does not elucidate which OI mode managers prefer for a particular project [7].

Most existing studies of OI mode selection have adopted firm- or industry-level perspectives. For example, some studies suggest that factors specific to a particular firm (e.g., firm size) or industry (e.g., environmental uncertainty) are critical contingencies for OI mode selection [8-10]. However, the findings drawn from such studies may prevent full understanding of OI mode selection, as they neglect the attributes of the problem that firms are attempting to solve through their innovation projects. Firms can use OI to address very different problems. For example, a wide variety of products, including cleaning products [11], energy storage devices [12], automobiles [13, 14], and commercial aircraft [15, 16], have come to fruition through various OI modes. Moreover, in a recent multiple case study, Brunswicker, et al. [12] showed that, even within the same firm, different problems are addressed using different OI modes. These differences in the same firm hint at the importance of considering problem attributes as a key driver in OI mode selection, and call for a downward theoretical shift in the level of analysis from firm- to project-level. Accordingly, West, et al. [17, p. $278]$ argued that "neither the practice of nor the research on open innovation is limited to the level of the firm."

Despite the theoretical and practical importance of understanding OI mode selection, project-level studies (i.e., problem-level analyses) on this important topic are still rare [18, 19]. Antons, et al. [18, p. 745] indicated that "most recent research on the hot topic of open innovation is based on a firm-level perspective 
and could be enriched by project-level studies." Only a few project-level conceptual studies have argued that problem attributes are likely to determine the appropriateness and fit of particular OI modes [7, 20, 21]. However, beyond these conceptual insights, the topic remains empirically underexplored, mainly due to a lack of access to fine-grained, detailed project-level data on OI activities [22]. To address this research gap, our article provides a comparative empirical cross-project analysis answering the following question: how do key problem attributes influence the governance of OI projects?

One such key attribute is problem complexity $[7,20]$. In complex problems, a large number of highly interdependent technical and market related elements interact in a non-simple way [23, 24]. Another key attribute, knowledge hiddenness, refers to the extent "to which the sources or location of knowledge deemed relevant for the problem are known to the manager" [7, p. 917]. Depending on these key problem attributes, firms may choose OI modes that provide extensive communication and knowledge exchanges, (e.g., equity and non-equity partnerships) [7], or OI modes that allow the participation of a large number of potential problem solvers, (e.g., OI contests, OI challenges, and OI intermediaries) [25, 26].

However, firms rarely consider only the fit between problem attributes and OI mode benefits. Each OI mode, whether a platform or an equity partnership, is associated with different transaction and set-up costs. If we assume that managers try to act rationally, then they will consider not only the benefits but also the costs of an OI mode in the decision-making process [27, 28]. Thus, OI scholars and practitioners need to understand how the interplay between problem attributes (i.e., complexity and knowledge hiddenness) and cost-benefit profiles of various OI modes drive OI mode selection.

We collected data via an online survey of 85 OI projects by large firms based in the USA and Europe, on which we conducted a set of cluster analyses and the Chi-square and binominal test. The results of the study reveal a clear link between problem attributes and firms' choices of OI mode. To explain these results, we draw on the cost-benefit profile of each OI mode and provide a set of illustrative cases. The paper makes four main contributions. First, our study adds to the literature on OI mode selection by providing valuable empirical insights that advance the conceptual conversation regarding the impact of problem attributes on OI mode 
selection. In addition, this project-level study contributes to the field of OI in general, and OI governance in particular, by showing the importance of considering the micro-foundations of OI (i.e., project attributes) to provide more stable results than higher-level factors (i.e., industry and firm). Second, we propose that the benefits-costs profile of each OI mode helps considerably to understand the appropriateness and fit of OI modes for projects characterized by different attributes. Third, we suggest that the two project attributes are related to OI mode selection not only separately but also in combination. We show that considering only individual effects can limit understanding of how project attributes affect OI mode selection. Finally, we contribute to the literature by arguing that a complex problem may be decomposed into sub-problems only when the knowledge sets required for sub-problem solving exist, and firms know of them. Thus, problem decomposition does not depend exclusively on problem complexity. Instead, the interaction between complexity and knowledge hiddenness drives problem decomposition decisions. Apart from these theoretical contributions, our results have important managerial implications. They provide managers with an empirically supported decisionmaking framework to guide OI mode selection.

\section{THEORETICAL BACKGROUND}

In this section, we develop the theoretical arguments that ground our empirical exploration of the impact of problem attributes on OI mode selection. We integrate two theoretical views on OI governance mode: (1) problem-solving view [7, 29] and (2) transaction cost view [30] to discuss problem attributes and OI modes theoretically.

\subsection{Problem Attributes}

Extensive research has investigated the organization and implementation of OI at the firm level (i.e., firm-centric view) $[6,19,31,32]$. However, recent works on OI have called for project-level analyses (i.e., problem-centric view) $[18,33]$, since problems can be very different in nature, even within the same firm [12]. OI is generally conducted to find an effective and efficient solution to a specific problem [34-36]. Previous studies [21,37] considered problem complexity as a key attribute affecting OI mode selection. In addition to 
problem complexity, in a recent conceptual study of OI modes, Felin and Zenger [7] identified knowledge hiddenness as another key attribute driving OI mode selection. In this study, we focus on these two problem attributes as key drivers of OI mode selection.

Problem complexity is defined based on the number of tasks and elements involved and the degree of interdependency between them [23, 24]. Complex problems comprise a large number of highly interdependent tasks and elements, implying that the final solution is influenced by multiple factors. According to Gavetti and Levinthal [38], complex problems require a theory-driven solution search, in which the problem solvers evaluate potential solutions and their underlying mechanisms conceptually, before any solution is actually implemented. Conversely, simple (i.e., not complex) problems usually require a directional solution search, a process guided by trial-and-error testing of various solutions [38]. Prior research holds that, as problem complexity increases, the degree to which the problem can be decomposed into independent sub-problems decreases, since one element of the solution might influence another, and also the overall value of the solution $[23,29]$. Solutions to complex problems are likely to take the form of complex systems, for which "the whole is more than the sum of the parts, not in an ultimate, metaphysical sense, but in the important pragmatic sense that, given the properties of the parts and the laws of their interaction, it is not a trivial matter to infer the properties of the whole" [23, p. 468]. Such complex systems tend to be hierarchical, that is, they comprise multiple sub-systems that further consist of sub-systems of their own, and so on [23]. Due to this hierarchy, many complex systems can be considered nearly decomposable [23]. For such system, the main sub-systems can be identified, but the interactions between these sub-systems cannot be easily anticipated. While the neardecomposability of a problem helps the focal firm collaborate with outsiders to develop sub-systems, decomposing complex problems can lead to sub-systems integration difficulties that damage the project outcome. For example, the development of a new commercial aircraft is clearly a highly complex problem due to the large number of highly interconnected and interdependent components and sub-systems involved. Despite these high levels of complexity, companies like Boeing divide their aircraft-development projects into sub-systems, whose development is often outsourced to independent contractors $[15,16]$. The decomposition 
of complex projects into sub-systems generally implies that the flagship company (i.e., the company coordinating the problem-solving process, in our example Boeing) is responsible for costly and timeconsuming system integration work to ensure that the sub-systems function together seamlessly and without friction $[16,39]$.

Knowledge hiddenness is defined in terms of the degree to which the sources or locations of knowledge deemed relevant to the problem at hand are known to project team members [7]. Sometimes, project team members do not know which external partners have the knowledge and ability required to solve their problem. This knowledge hiddenness makes it extremely difficult to solve the problem, as firms cannot start collaborating or sign contracts until they have identified external partners (i.e., individuals or companies) with the relevant knowledge set. At this stage, we need to stress that knowledge hiddenness is different yet related to the idea that knowledge is often spread across multiple partners. Scholars have long acknowledged the distributed nature of knowledge as the force driving the transition from closed to open innovation [40]. However, when distributed knowledge is hidden, firms may find it difficult to manage and advance the problem-solving process. In such situations, the only viable OI modes may be those encouraging holders of relevant knowledge to reveal themselves, such as OI contests and challenges [7].

\subsection{OI Modes}

As mentioned earlier, firms can choose a variety of OI modes to tap into the knowledge of external partners [1, 5, 41]. While some firms opt for more traditional OI modes, such as alliances [42, 43], joint ventures [44], and licensing agreements [45], others use the crowd, adopting OI contests [25] or OI intermediaries [26] to solve a problem. In this article, we focus on four types of OI mode: (1) market-based contracts, (2) OI platforms, (3) non-equity partnerships, and (4) equity partnerships.

These four OI modes differ in their potential costs and benefits. We will consider two types of costs: set-up and transaction costs. By set-up costs, we refer to the initial investment required to establish the legal, organizational and physical framework for OI. This category can include fees paid to OI intermediaries [7], asset-specific and tooling investments [13], and equity investments [27]. For example, equity partnerships 
probably require the highest initial investment, while using OI platforms (conducting innovation contests intermediated by online platforms) involve a small initial investment. Transaction costs consist of coordination costs and opportunism costs. Coordination costs refer to the costs of "decomposing tasks among partners along with ongoing coordination of activities to be completed jointly or individually across organizational boundaries and the related extent of communication and decisions that would be necessary" [46, p. 782]. Transportation, division of tasks, communication, information processing, and negotiation are examples of coordination costs $[46,47]$. Opportunism costs are related to potential opportunistic behavior, as one partner might pursue their own goals at the expense of the other partner's or joint goals and intellectual property [46, 48, 49]. Examples of opportunism costs include knowledge disclosure, contract infringement, and contract enforcement [8, 46, 50]. In terms of the benefits provided by each OI mode, we will focus on: enhanced communication and knowledge sharing between partners [7, 29], and breadth of external partners, which refers to the number of external partners a firm can rely upon $[20,31,51]$. Drawing on the literature, we provide an overview of the cost-benefit profile for each OI mode in Table 1 and discuss these profiles in more detail below.

\section{----- INSERT TABLE 1 ABOUT HERE -----}

Market-based contracts are transactional arrangements (e.g., licensing agreements), usually with a single external partner who owns potential solutions or solution elements (e.g., a particular technology or knowledge set) relevant to the problem [52]. Through market-based contracts, the focal firms seek to match problems with external partners that already have potential solutions (or solution elements), or can develop them at mutually agreeable prices [7]. This mode allows focal firms to access relevant external technology and knowledge through transfers of intellectual property (IP) rights [7]. Because market-based contracts are straightforward transactions, set-up costs tend to be negligible. However, contract negotiation (e.g., reaching a mutually agreeable price) and enforcement can cause difficulties and, thereby, transaction costs [53]. In terms of benefits, this mode provides limited potential for communication between the focal firm and the external partners [7, 29]. As a result, knowledge exchange is usually restricted in a contractual relationship. For these reasons, prior conceptual studies suggest that a transactional approach to OI may be inappropriate for complex 
problems, which require a more collaborative approach for partners to grasp the problem's complex interdependencies [7]. Furthermore, the breadth of external partners is low in market-based contracts, since the focal firm's search efforts usually consist of requests for proposals (RFP) sent out to a limited number of external partners believed to possess potential solutions or solution elements [7].

OI Platforms access a large number of external partners (i.e., problem solvers) who potentially have relevant ideas, technologies, or knowledge to provide solutions or solution elements for the firms' problems, usually via an internet-based platform [20, 25]. OI platforms subsume modes such as OI contests, OI challenges, or OI competitions [7]. In many cases, focal firms opt for OI intermediaries managing independent third-party platforms [54-56], such as NineSigma and IdeaConnection, which have access to a large pool of problem solvers including creative individuals, specialists, and start-up companies [57]. These OI intermediaries offer focal firms the ability to access the long tail of possible solutions without having to manage the overall problem-solving process. The transaction costs of OI platforms are generally low, as OI intermediaries possess extensive coordination capabilities [7, 57] and usually enter separate contractual relationships with the focal firm advertising problems to be solved, and with problem solvers. Once a viable solution or solution element emerges, the OI service provider intermediates a contract between the focal firm and the solution provider, which the transfers the IP rights for the solution to the focal firm. OI intermediaries usually charge a commission based on the value of the contract transferring IP rights from problem solver to focal firm. The set-up costs involved in this mode are low, comprising fees paid to OI intermediaries to crowdsource and advertise the focal firm's problem. In terms of benefits, OI platforms bring more eyeballs to the problem by broadcasting the problem to a large pool of potential problem solvers [25]. This diverse crowd may provide access to hidden and unexpected knowledge and ideas of which internal project team members were not aware at the beginning of the project. However, this mode does not provide deep interactions between focal firm and problem solvers. As a result, this mode provides access to a wide variety of problem solvers, but with limited knowledge sharing. 
Non-equity partnerships (i.e., alliances) include collaborations within a dyad or network of external partners, such as suppliers, universities and competitors [41, 42]. Non-equity partnerships often require highly complicated contracts (e.g., Risk and Revenue Sharing Partnerships, frequently used in the aerospace industry, see Lawrence and Thornton [15]; Norris and Wagner [16]), which are difficult to negotiate and enforce, implying high transaction costs. Non-equity partnerships may also require considerable set-up costs, as external partners often ask for advance payments from the focal (or flagship) firm to (partially) cover their R\&D and tooling costs [13]. Moreover, in a non-equity partnership, suppliers may also demand that the focal firm commits to purchasing large volumes of original design components to defray development and tooling costs [13]. In terms of benefits, non-equity partnerships provide a rich communication channel between focal firm and external partners, supporting knowledge sharing [7]. This mode can also provide access to a wide range of external partners, depending on the scope of the partnership [41, 58].

Equity partnerships include joint ventures (JVs), consortia, and minority holdings [8, 44]. While equitybased partnerships often involve massive initial capital investments (i.e., set-up costs) [27], equity control (exercised through a joint board or decision-making committee) generally reduces the risk of opportunistic behavior among partners and the coordination costs, reducing the overall transaction costs $[53,59,60]$. The closeness of equity-based relationships supports extensive communication and knowledge sharing (both tacit and explicit) $[60,61]$. However, the number of external partners tends to be limited. Consortia (the broadest form of equity partnership), such as Microelectronics Joint Development Venture, the semiconductor technology-focused consortium including IBM, Siemens, Samsung, Freescale and Infineon [21], usually involve no more than a handful of external partners.

Overall, partnerships support more extensive communication and knowledge sharing between the focal firm and its external partners than market-based contracts and OI platforms, but also involve higher transaction costs (non-equity partnerships) or set-up costs (both equity and non-equity partnerships). Equity partnerships have lower transaction costs than non-equity partnerships, but require higher set-up costs. OI platforms provide 
access to a wider range of external partners, but less communication and knowledge sharing than partnerships and market-based contracts.

\subsection{Matching Problem Attributes and OI Modes: An Exploratory Approach}

As we argued earlier, problem attributes are important drivers of OI mode selection. For example, complex problems may require an OI mode that favors communication and collaboration. We also argued that OI modes differ in terms of cost and benefits provided (see Table 1). For instance, equity partnerships can help the focal firm achieve extensive communication and knowledge sharing with their external partners, but require the focal firm to make massive initial investments (i.e., set-up costs). Clearly, the interplay between problem attributes and cost-benefit profiles of OI modes has a critical impact on OI mode selection.

To understand this interplay, we must change the level of our analysis from industries and firms to projects (i.e., problems). As it depends on problem attributes, OI mode selection is an artifact of lower level antecedents, and studies cannot assume project homogeneity [62]. Consequently, to capture project-level heterogeneity in problem complexity and knowledge hiddenness, researchers must focus on the microfoundations of OI, which may provide more stable and fundamental explanations than macro- and meso-level analyses [62]. However, conspicuously few project-level empirical studies on the topic appear in the OI literature, most likely due to problems of access to fine-grained, detailed project-level data on OI activities [18, 33]. Moreover, project-level conceptual studies of OI modes are sparse (e.g., [7, 21]), making theorizing on the topic particularly difficult. This lack of empirical studies and insights on the topic and of conceptual discussions calls for an exploratory study to deepen understanding of the role of problem attributes in OI mode selection.

Following a tradition of exploratory studies focusing on empirically under-researched topics with limited theoretical and practical insights $[63,64]$, this study aims to compare different projects with the ultimate goal of providing novel, insightful empirical evidence about OI mode selection. We suggest that shifting the level of analysis to explore the phenomenon from a different perspective (i.e., project-level perspective) will likely have major implications for both OI scholarship and practice. 


\section{METHODOLOGY}

\subsection{Data Collection and Sample}

To address our research question, we collected data through an online survey of a cross-industry sample of OI projects. The firms conducting these projects are large (annual revenues exceeding \$250 million and more than 1,000 employees) and listed on the stock exchange in Europe or the USA. We chose to focus on large firms because they are more likely to undertake major innovation projects involving external partners. We collected the data between December 2014 and August 2015. First, we sent the survey to senior executives (e.g., Chief Executive Officers and Chief Technology Officers) as primary contacts at the firms' headquarters. We asked them to select at least one OI project that they have completed within the last two years. We focused on recent OI projects to ensure that respondents remembered the project details when completing the survey. To minimize informant bias, we asked our primary contacts to assign the most suitable respondent for the selected OI project (e.g., project manager) to complete the survey [65]. To increase the response rate, we sent four follow-up emails to firms that did not complete the survey and then called the contacts.

Eventually, 59 firms completed the survey for 104 OI projects. 45 firms completed the survey for two OI projects (one respondent per project for each of the 45 firms), while 14 firms completed the survey for only one OI project (one respondent per project). We compared key problem attributes of OI projects conducted by early and late respondents to test late-response bias by the ANOVA test (analysis of variance). The results showed no significant differences in terms of problem complexity and knowledge hiddenness, confirming the absence of late-response bias. ${ }^{1}$ We had some missing values for variables related to OI modes. We performed the two-sample T-test to examine whether there were systematic differences in terms of other observed variables in this study (i.e., the two problem attributes) between OI projects with and without missing values. We found no significant differences, and OI modes for some projects are missing completely at random. Therefore, we could exclude the 19 OI projects with missing values from the sample [66], reducing the final sample to 85 OI projects.

\footnotetext{
${ }^{1}$ Detailed results of these analyses are available from the authors on request.
} 


\subsection{Measures}

We developed measures for the problem attributes based on their definitions. We also adapted measures of OI modes used in previous studies. To refine the measures, two researchers working in OI (one of whom is also an expert in survey development) reviewed them. Before sending out the survey, we conducted a pilot test with three senior managers (one $\mathrm{CEO}$ and two CIOs) for further refinement. The results of the item review and pilot test led to a few minor revisions of the initial questionnaire.

To measure problem complexity, we asked respondents to describe the problem being solved in the selected OI project using two items on a seven-point Likert scale, between 1 "Strongly Disagree" and 7 "Strongly Agree": (1) it involved a large number of highly interdependent tasks (that could not be completed independently); (2) new tasks and interdependencies between them emerged unexpectedly. The correlation (Pearson correlation coefficient $=0.552$ with $\mathrm{p}$-value $<0.001$ ) between these two items was higher than the accepted cut-off value of 0.25 [67], confirming adequate internal consistency. We calculated the average of the two items to measure problem complexity.

We measured knowledge hiddenness based on the single item "we were able to identify the know-how required to solve the problem before we started interacting with external sources." We asked respondents to rate this item for the selected OI project on a seven-point Likert scale between 1, "Strongly Disagree," and 7, "Strongly Agree".

Then, respondents selected from a list the OI modes that they adopted in their project. The OI mode list included: (1) bilateral contract with an external source (e.g., licensing contract); (2) contest with an open call to the 'world' for submissions or open innovation intermediaries (e.g., Ninesigma), who linked the firm with a network of external innovators; and (3) collaborative agreement with multiple partners (e.g., consortia agreements) (adapted from [1]). Respondents could select multiple OI modes for each project. Finally, to measure non-equity and equity partnerships, respondents assessed the selected OI project by answering (Yes/No) to the single question "Did you have any equity control through a joint board and committee in interaction with your external sources?" 


\section{DATA ANALYSIS AND RESULTS}

In the following sections, we present our empirical evidence, showing how two key problem attributes, complexity and knowledge hiddenness, drive OI mode selection. Given the nature of our study, we conducted a three-step exploratory statistical analysis. First, we developed a set of homogeneous clusters of OI projects involving similar problems. Second, we clustered OI projects based on the OI mode adopted, to develop homogenous groups of projects. Finally, we explored whether and how the two problem attributes are related to OI modes through cross-tabulation and by conducting the Chi-square and binominal test [68, 69].

\subsection{Problem Attributes: An Empirical Typology of OI Projects}

Below, we present our emerging typology of OI projects based on the two problem attributes. Our aim was to classify the 85 OI projects into a set of homogeneous clusters based on problem attributes. On average, the projects in our sample were high in complexity and moderate in knowledge hiddenness. The mean values for problem complexity and knowledge hiddenness are 5.02 (standard deviation $=1.48$ ) and 3.53 (standard deviation $=1.86$ ), respectively. These two problem attributes are not correlated (Pearson correlation coefficient $=-0.059$ with $\mathrm{p}$-value $=0.592$ ), suggesting that problem complexity and knowledge hiddenness are distinct problem attributes. Therefore, multicollinearity, which is a notable difficulty in cluster analysis, and may overweight one of the variables, is not an issue in this study [70].

Following Hair, et al. [68], we performed a two-step procedure (i.e., hierarchical and non-hierarchical K-means methods in a sequential manner) to cluster the 85 OI projects using the two problem attributes. Since our variables for project attributes are continuous, we applied hierarchical and non- hierarchical cluster analysis, as recommended by Hair, et al. [68]. We first conducted a hierarchical cluster analysis, applying the most commonly used Ward's method, which provides the most homogenous results within a cluster and heterogonous results across clusters, and the squared Euclidian distance measure [68, 71]. To decide on the number of clusters, we relied on agglomeration coefficients plotted over the number of clusters, and also inspected the dendrogram [71]. Based on the results, we took three cluster seeds (i.e., three-cluster, four-cluster, and five-cluster solutions) to define a starting solution for the non-hierarchical K-means method [70]. After 
conducting the non-hierarchical K-means method, we investigated the interrater reliability of these three cluster solutions, achieved by performing the hierarchical and the non-hierarchical K-means methods, using Cramer's $\mathrm{V}$, which is a Chi-square based measure of association between nominal variables [68]. We found the highest degree of consistency between the two clustering methods for the four-cluster solution (with a Cramer's V of 0.79). Following Ketchen and Shook [71], we applied other methods in addition to Ward's method for the fourcluster solution, using between-group linkage, within-group linkage and centroid clustering to check the degree of consistency between solutions (i.e., reliability). The results showed a high degree of consistency for the four-cluster solution achieved using different hierarchical clustering methods (e.g., centroid clustering and Ward's method with a Cramer's V of 0.71), demonstrating the reliability of the four clusters of OI projects. Thus, the four-cluster solution seemed the most appropriate.

We present the means for the complexity and knowledge hiddenness attributes of each cluster in Table 2. To identify which clusters were significantly different based on the two problem attributes, and to check the validity of the four-cluster solution, we applied the ANOVA test and the two-sample T-test, as the project attribute variables are continuous [68]. Based on the ANOVA, the two problem attributes showed significant differences between the four types of projects (presented in Table 2). Also, the two-sample T-test showed that projects in types 3 and 4 are significantly more complex than those in types 1 and 2 . The knowledge required for OI projects is more hidden (more unknown) in types 2 and 4 than in types 1 and 3 (presented in Table 2). These types of projects show that firms in our sample engaged in OI projects with different levels of problem complexity and knowledge hiddenness.

\section{----- INSERT TABLE 2 ABOUT HERE -----}

Project Type 1: Simple problems for which the relevant knowledge is not hidden. $22.4 \%$ of the OI projects in our sample involve relatively simple problems. The problems can be delineated, described, and translated into requirements, as the tasks and elements influencing the solutions seem manageable and are not highly interdependent. Moreover, in type 1 projects, the project team members are aware of the location of relevant knowledge. In other words, the solution knowledge is not hidden from project team members. 
Project Type 2: Simple problems for which the relevant knowledge is hidden. Like type 1 projects, OI projects in our type 2 (17.6\% of the OI projects in our sample) are relatively simple, with tasks and elements that are not particularly interdependent. However, unlike type 1 projects, the location of the relevant knowledge is unknown to project team members. They cannot identify the relevant solution knowledge, even though they can describe the problem.

Project Type 3: Complex problems for which the relevant knowledge is not hidden. Type 3 projects (34\% of the OI projects in our sample) deal with relatively complex problems involving a large number of different tasks and elements that are highly interdependent. Despite this complexity, the project team members are aware of the location of the knowledge required to solve the problem. The challenge for type 3 projects lies in tackling the complexity of the problem space.

Project Type 4: Complex problems for which the relevant knowledge is hidden. OI projects in this type ( $26 \%$ of the OI projects in our sample) are relatively complex, like type 3 projects. In addition, the location of the knowledge required to solve the problem is unknown to project team members, as in type 2 projects.

\subsection{OI Modes: An Empirical Typology of OI Projects}

As it was possible for respondents to select multiple OI modes they had adopted for the selected OI project to leverage the knowledge of external partners, in the second step of our exploratory statistical analysis, we classified OI projects with respect to OI modes, including market-based contracts, OI platforms, equity and non-equity partnerships. We discovered that firms use market-based contracts (77.6\%) and non-equity partnerships (38.8\%) more often than equity partnerships (17.6\%) and OI platforms (25.9\%) in their projects.

We performed a two-step cluster analysis, using a log-likelihood similarity measure, to group 85 OI projects into clusters based on their adopted OI modes. We applied a two-step cluster analysis, as our OI mode variables are categorical (adopted or not for the selected project). This method can cluster categorical variables, unlike other methods of clustering, such as hierarchical and non- hierarchical cluster analysis, which require continuous variables [68]. We used the model-choice criterion to explore the ideal number of clusters suggested by this clustering method. The Akaike Information Criterion (AIC) and Bayesian Information Criterion (BIC) 
suggested a four cluster solution with a cluster quality of 0.7 (i.e., Silhouette measure of cohesion and separation). Table 3 shows the four clusters of projects with respect to the OI modes adopted. To check the validity of the four-cluster solution, we conducted the Chi-square test to check whether the four clusters were significantly different depending on each OI mode (i.e., association between nominal variables) [68]. The adoption of each OI mode showed significant differences between four clusters. Thus, each cluster represents a project category in which one OI mode dominates.

\section{----- INSERT TABLE 3 ABOUT HERE -----}

Our results show that $32.9 \%$ of the projects in our sample fit into a cluster in which markets-based contracts are predominant. The second cluster consists of projects that relied heavily on OI platforms and represents $21.2 \%$ of our sample. The third cluster (29.4\% of sample) includes projects involving non-equity partnerships. The last cluster represents $16.5 \%$ of our sample, and it is dominated by equity partnerships.

\subsection{Empirical Evidence on the Relationship between Problem Attributes and OI Modes}

Thereafter and building upon the clusters we discovered based on problem attributes (four types of projects) and OI modes (four clusters), we explored how problem attributes relate to OI modes. To do so, we generated a cross-tabulation of these two variables by including the observed frequency of projects in our sample, for each of 16 possible categories (i.e., cells). Then, we calculated the expected frequency for each cell under the assumption that there is no relationship between the projects attributes and the OI modes (i.e., they are statistically independent) [68]. Table 4 presents the observed and expected frequency in each cell.

\section{----- INSERT TABLE 4 ABOUT HERE -----}

The result of Chi-square test reveals that there is a significant difference between the expected and observed frequencies in the cross-tabulation (Chi-square $=19.953, \mathrm{p}$-value $=0.018$ ), thereby the project attributes and OI modes are dependent. This shows that the preferred OI mode is different for different types of projects. Then, we used the binominal test [69] to test whether the difference between the observed and expected frequency in each cell is statistically significant. The results show that this difference is significant for some cells (presented in Table 4 where the p-value for significant cell is bolded), indicating that firms prefer 
to adopt a specific OI mode for a certain project type. In cell 22, the observed frequency (6) exceeds the expectation (3.176) and this difference is significant ( $\mathrm{p}$-value $=0.099$ ). This suggests that firms prefer OI platforms for projects involving simple problems with high levels of knowledge hiddenness (project type 2). Moreover, in cell 32, the observed frequency (2) is lower than the expected (6.141) (the difference is significant with $\mathrm{p}$-value $=0.05)$, indicating that firms prefer not to apply OI platforms for complex projects for which the required knowledge is not hidden (project type 3). In cell 33, the observed frequency (15) is higher than expected (8.529), indicating that firms tend to adopt non-equity partnerships for projects involving complex problems for which relevant knowledge is not hidden (project type 3) (the difference is significant with p-value $=0.022$ ). Our results show that firms avoid non-equity partnerships for simple problems with a low level of knowledge hiddenness (project type 1), as the observed frequency (2) is lower than expected (5.588) (the difference is significant with p-value $=0.076)$. Finally, in cell 44 , the observed frequency $(7)$ exceeds the expectation (3.624) and the difference is significant with $\mathrm{p}$-value $=0.071$. This result shows that firms prefer equity partnerships when dealing with complex problems for which the location of required knowledge is unknown (project type 4). Below, we use a set of illustrative cases (i.e., OI projects) to discuss our empirical findings, which suggest a clear relationship between the types of projects and the preferred OI modes.

\section{Market-based contracts for simple problems for which relevant knowledge is not hidden}

Our findings show that, in 8 out of 19 projects dealing with relatively simple problems where the relevant knowledge can be easily located (observed frequency exceeds expectation, although the difference is not statistically significant), firms adopted market-based contracts, such as licensing agreements, to leverage the relevant knowledge from outsiders. To illustrate such a market-based transaction, we draw on the case of Clariant, the Switzerland-based world leader in specialty chemical manufacturing. Clariant wanted to complement its ActiSorb adsorbent product segment to provide comprehensive solutions meeting clients' requirements for greater efficiency in the purification of hydrocarbon feedstocks ${ }^{2}$. Feedstocks are raw materials

\footnotetext{
${ }^{2}<$ http://www.catalysts.clariant.com/bu/Catalysis/internet.nsf/023cfbb98594ad5bc12564e400555162/1f2fbe0521d9fc23c1257b1e0 032460f?OpenDocument $>$.
} 
constituting the principal input for a machine, plant or industrial process. Ethylene, propylene, butadiene, benzene, and toluene are examples of hydrocarbon feedstocks. Developing a new technology for purification of hydrocarbon feedstocks is an example of relatively simple problem as it did not involve highly interdependent knowledge sets. Moreover, Clariant were aware of a fast and safe technology for removing mercury from natural gas that would provide a technical solution for their problem. This technology had been developed by a team at Queen's University Ionic Liquid Laboratories (Quill - UK) in collaboration with the Malaysian oil and gas company, Petronas, and was called "HycaPure $\mathrm{Hg}^{\prime}$ technology ${ }^{3}$. Petronas' Vice President for Technology and Engineering stated the technology was “already used at Petronas's gas processing

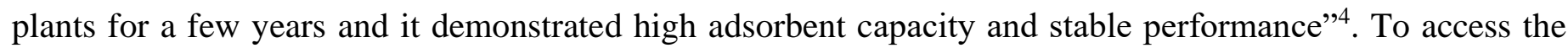
required technology for their problem, Clariant negotiated a licensing agreement with Petronas by which Clariant could use Petronas' "HycaPure Hg" technology for removing mercury from natural gas as a complement for its portfolio of ActiSorb series adsorbents ${ }^{5}$ to remove impurities from hydrocarbon feedstocks.

Our empirical exploration is in line with the existing conceptual papers in the OI literature [7, 21]. Through market-based contracts (e.g., licensing agreements), the focal firms swiftly match their lowcomplexity problems with external solutions developed by independent third parties [7]. Low set-up costs make market-based contracts involving IP rights more attractive than other types of OI partnerships. Moreover, communication and knowledge exchange between the focal firm and the external partners (i.e., benefits provided by OI partnerships) are not essential for simple problems, which involve one or few independent knowledge sets. Some firms may find market-based contracts preferable to OI platforms when dealing with simple problems with low levels of knowledge hiddenness (type 1 projects) because they allow the immediate selection of existing solutions provided by trusted elite players as opposed to reviewing and testing numerous solutions proposed by contributors of uncertain reputation [21]. However, our results also show that for 6 out

\footnotetext{
${ }_{3}<$ http://www.rsc.org/chemistryworld/2015/03/mercury-removal-ionic-liquid-natural-gas $>$.

$4<\underline{\text { http://www.chemanager-online.com/en/news-opinions/headlines/clariant-and-petronas-sign-licensing-collaboration }>.}$

${ }^{5}<$ http://www.catalysts.clariant.com/C12576850036A6E9/2B45555E0DD48E3AC1257CA800227169/\$FILE/clariant-andpetronas-sign-licensing-collaboration_en.pdf>.
} 
of 19 type 1 projects, firms preferred OI platforms (observed frequency exceeding expectation, although the difference is not statistically significant). One explanation behind this result may be that, although firms think that they know the location of relevant knowledge, they rely on OI platforms to ensure that they have indeed identified the optimal solution and other better solutions are not available. Alternatively, firms may rely on OI platforms for type 1 projects in order to identify new solution providers (in addition to those already known). A greater number of competing solution providers would likely increase the bargaining power of focal firms. Both of the explanations above are plausible, given the relatively low initial investments required by OI platforms.

\section{OI platforms for simple problems for which relevant knowledge is hidden}

Our analysis shows that firms adopt OI platforms for projects dealing with simple problems for which the required knowledge cannot be easily located (type 2 projects). These are simple but obscure projects for which the focal firms cannot identify the right solution knowledge, even though they can describe the problem. An example of problem that falls into this category is Pfizer's prefilled syringes project. In this case, Pfizer aimed to design a tech-enabled locker for prefilled syringes. Essentially, this was a way to ensure that people taking medication by use of a syringe are actually adhering to prescribed protocol doses [12]. The design of the syringe locker was a relatively simple problem as it was well defined and independent from other technical or market-related factors and challenges. However, this project required novel solution concepts and the optimal solution was unknown to Pfizer [12]. Even though Pfizer had developed several designs before, none of the in-house designs provided an effective solution [12]. The solution for this project emerged through an OI platform, which advertised the innovation problem and encouraged competition within "the crowd" with the hope of eventually discovering a solution. Pfizer decided to work with IdeaConnection, an OI intermediary that delivers timely and cost-effective solutions to their clients. Pfizer paid a service fee to IdeaConnection (i.e., set-up cost) to establish a competition situation among the participating problem solvers. As Pfizer needed to ensure that it would have the option to gain usage rights for the solution provided by the external problem solver, the negotiation of IP rights was a source of transaction costs in this case. 
These findings are in line with conceptual research on the topic [7, 21]. OI platforms allow the focal firms to crowdsource their problems and solicit the support and participation of numerous problem-solvers who are invited to reveal themselves and showcase their knowledge and capabilities. In terms of the breath of external partners, OI platforms are unrivalled by market-based contracts or partnerships. The benefits stemming from accessing a wide variety of otherwise hidden knowledge sources make up for the slightly higher set-up costs involved by OI platforms (i.e., the service fee paid to the platform intermediary) compared to market-based contracts. As the problems are simple and do not involve interdependent tasks and elements, the solutions proposed by problem solvers of uncertain reputation can be evaluated and tested without incurring significant efforts and costs. Partnerships do not seem appropriate for this type of project. Partnerships involve superior transaction and set-up costs, while their main benefits, i.e., communication and knowledge exchange between the focal firm and external partners, are not relevant for solving simple problems.

\section{Non-equity partnerships for complex problems for which relevant knowledge is not hidden}

When faced with complex problems for which they can locate the required knowledge, firms seem to prefer non-equity partnerships. Here, the emphasis falls on the complexity of the problem, as many tasks and elements interact in complex ways and influence the solution. This was the case in late 2002, when Boeing decided to develop their 787 Dreamliner as a strategic response to Airbus' A380 superjumbo, the world's largest passenger airliner. As the Dreamliner, a mid-size aircraft, was expected to cover distances exceeding $15.000 \mathrm{~km}$ just like the A380 did, Boeing decided to make it lighter than any plane of comparable size. To achieve this, more than $50 \%$ of the aircraft was constructed from lightweight carbon fiber composite [39]. Since past airliners had been constructed from aluminum, Boeing did not have the required expertise with composite materials. Consequently, the American aircraft manufacturer entered non-equity partnerships with Japan's Mitsubishi and Kawasaki and Italy's Alenia $[15,16]$. Mitsubishi was in charge of the development and manufacturing of the composite wings, while Kawasaki and Alenia developed most of the fuselage [16]. Moreover, it was UK's Rolls Royce that developed and produced the Dreamliner's innovative thrust engines which were some $20 \%$ more fuel efficient than previous generation engines [16]. Nor were these the only non- 
equity partnerships that Boeing entered for the Dreamliner project. Companies such as Sweden's Saab, France's Latecoere, Korea's KAL-ASD, UK's Messier-Dowty and American Goodrich and Spirit were among the 50 tier-1 strategic partners who acted as "pre-integrators" of original subsystems and components developed by tier-2 suppliers [39]. Some $65 \%$ of the Dreamliner's components were developed by external partners [15]. Thus, despite dealing with a highly complex problem (i.e., developing a new passenger aircraft), Boeing decided to divide the project into sub-systems (e.g., wings, thrust engines, tail part of the fuselage, etc.) corresponding to the capabilities and expertise of its strategic partners. It is worth mentioning that Boeing could easily identify strategic partners possessing relevant knowledge as it had prior working relationships with most of them.

The global innovation network [72] supporting the development of the Dreamliner was managed through a risk and revenue sharing partnership (RRSP) [39]. In such partnerships, the tier-1 strategic partners are paid only when the final product, in this case the 787 Dreamliner, is delivered to customers [39]. This type of partnership is designed to ensure that the strategic partners collaborate and coordinate their own development efforts as well as those of tier-2 suppliers. The main benefit provided by RRSP to the strategic partners is that they retain their intellectual property, which can later be licensed to third parties [39]. Given the complex nature of RRSP in terms of division of tasks, communication and negotiation, it can be argued that the coordination costs incurred in the 787 Dreamliner project were significant.

Compared to equity partnerships, non-equity partnerships hold several advantages: (1) they do not require a massive equity investment, (2) they reduce development costs and lead times, and (3) they allow the focal company to leverage the knowledge, expertise and manufacturing capabilities of a far larger number of partners (i.e., breadth of external partners). Moreover, non-equity partnerships are more appropriate for addressing complex problems than market-based contracts. As complex problems consist of numerous interdependent elements, tasks and knowledge sets, they require significant integration work to ensure that systems and subsystems act seamlessly as a whole and perform the intended task. Such integration work is possible only through extensive communication and exchanges of tacit and explicit knowledge, which are not 
provided by market-based contracts nor when using OI platforms. In the Dreamliner case, Boeing facilitated communication and exchange of knowledge through an online system called Exostar that enhanced supply chain visibility, quality control and system integration [39]. However, despite all these communication- and cooperation-enhancing efforts, Boeing still faced major difficulties when trying to integrate the original designs of the sub-systems provided by its strategic partners. Due to these integration problems the launch of the Dreamliner was delayed by about three years [73]. Thus, while dividing complex projects into sub-systems may be difficult and can cause major integration problems [74], it seems that firms prefer non-equity partnerships as long as they can identify appropriate partners (i.e., low levels of knowledge hiddenness). In such cases, firms appear more willing to accept high coordination and integration costs rather than the high set-up costs required by equity partnerships.

\section{Equity partnerships for complex problems for which relevant knowledge is hidden}

Our exploratory study further shows that, when attempting to solve a complex problem for which the relevant knowledge is unknown, firms tend to form equity-based partnerships. For example, in the 1990s, deep ultraviolet (DUV) lithography technology was used to manufacture computer chips. Firms like Intel and Samsung relied on DUV light at 243-nanometer wavelengths to project integrated circuit patterns onto semiconductor wafers. In order to increase the computing power of chips, more and more features had to be imprinted on the wafer. In turn, this meant that the features and patterns had to become smaller and smaller $[75,76]$. At the end of the 1990s, it became clear that extant DUV lithography would soon reach its limitations as the technology did not allow for further size reductions of the circuit patterns [76]. At the time, several lithography technologies showed promise in the race for the next generation of microchips. Extreme ultraviolet (EUV) light was favored by Intel, X-ray lithography was preferred by IBM and Mitsubishi, while Lucent Technologies/Bell Labs banked on electron-beam systems [75, 77]. Although promising in their own right, each of these technologies was in its infancy and extensive bodies of new knowledge were required in order to make these technologies viable solutions for microchip manufacturing. To pursue the EUV technological path that it envisioned, Intel initiated EUV Limited Liability Company (LLC), a consortium in which Advanced 
Micro Devices and Motorola were the other original partners. Micron Technology, Infineon Technologies and IBM subsequently joined the consortium $[76,78]$. The purpose of EUV LLC was to demonstrate the viability of the EUV technology [76] and, thereby, set the next technology standard for the microchip industry. The EUV technology posed numerous interrelated problems: (1) in the EUV spectrum (i.e., wavelengths around 13 nanometers), light was absorbed instead of transmitted by conventional lenses and, thus, completely new lenses needed to be developed, (2) since all materials, including oxygen, absorbed EUV light, any production equipment using this technology had to operate in vacuum, (3) EUV production lines required an estimated 250-watt power which was difficult to attain and (4) the inspection technology, which allowed to check for printing defects in circuit patterns of 10 nanometers or less, was a cumbersome research project in itself [75, 79]. In this case, the relevant knowledge was clearly hidden as it was yet to be developed. To achieve its goal, EUV LLC provided funding and project-management capabilities for the creation of a "virtual national laboratory" consisting of researchers from three US Department of Energy national laboratories - Lawrence Livermore, Lawrence Berkeley and Sandia/California [75, 80].

Drawing on this example, we can identify the main reasons why firms seem to prefer equity partnerships to other types of OI governance modes, when addressing problems with high levels of both complexity and knowledge hiddenness. First, in such cases, dividing the problem into discreet sub-problems becomes unfeasible. While we have seen in the Boeing example that breaking down complex problems may be possible despite the interdependencies between parts and subsystems, such problem decomposition makes sense only when partners with the required knowledge to develop and design the sub-systems are known to the focal firm. The difficulties and shortcomings posed by the decomposition of complex problems can be addressed through system integration work (again, see the Boeing example). However, in the absence of partners with relevant knowledge, decomposition may not provide any development cost reductions and time-to-market benefits. Thus, we argue that the interplay between problem complexity and knowledge hiddenness is critical for decomposition-related decisions, and not complexity on its own as suggested by previous studies (see [29]). Second, when the relevant knowledge is non-existent or unavailable, the transaction costs involved by non- 
equity partnerships can be significant as it is very difficult to draft and negotiate comprehensive contracts governing these partnerships under conditions of high technological uncertainty. Third, for this type of problems, equity partnerships are vastly superior to OI platforms in terms of communication and knowledge sharing. According to an insider in the EUV LLC project, "the concept [was] that by working together, in a very tightly coupled way, we will realize an alpha machine [prototype] much faster than if we were working separately" [80, p. 36]. Since the breadth of sources may be of less importance, firms may prefer to collaborate with elite players deemed more likely to contribute to the development of a viable solution (see [21]). Moreover, when dealing with complex problems, a wide breadth of external partners (as provided by OI platforms) may pose additional costs rather than provide benefits. It may often be too costly and time consuming (if possible at all) to evaluate and test numerous solutions (to complex problems) proposed by untrusted sources [21].

Overall, we suggest that, when high problem complexity overlaps with high knowledge hiddenness, equity partnerships may be the only feasible alternative, thus explaining the focal firms' choice of this OI mode despite its high set-up cost. Our empirical evidence and illustrative cases suggest that when knowledge hiddenness is reduced, firms prefer non-equity partnerships to equity ones. Drawing further from our EUV LLC example, we find that once significant progress was made with the technology via equity-based partnerships (i.e., knowledge hiddenness was reduced), EUV LLC established non-equity partnerships with experienced lithography equipment vendors, such as Silicon Valley Group and Ultratech Stepper Inc., for the development of EUV microchip manufacturing equipment [77].

\section{DISCUSSION and CONCLUSION}

This exploratory study contributes in several ways to the lively discussion on how to open up innovation projects. In particular, our research advances the theoretical discussion on OI governance and, equally importantly, has immediate practical implications.

\subsection{Theoretical Contributions}


First, by shifting the level of analysis from industries and firms to projects (i.e., problems), we provide rare empirical evidence illustrating how managers choose between various OI modes depending on the attributes of the problem that they are addressing. Thus, we contribute to the OI literature, particularly mode selection, which is currently dominated by conceptual studies, by pointing out the importance of studying the micro-foundations of OI. Such an analysis may provide more stable underlying explanations than previous industry- and firm-level analyses, by capturing project-level heterogeneity. This addresses the call by West and Bogers [33] and Antons, et al. [18] for further research on OI from the project-level perspective. In summary, we show that managers tend to use market-based contracts to tackle simple problems for which relevant knowledge is easy to locate (i.e., low levels of hiddenness), while OI platforms are their preferred vehicle for addressing simple problems when relevant knowledge remains elusive. Our empirical exploration related to these two OI modes is in line with conceptual papers in the OI field [7,21]. Further, we show that managers favor partnerships when dealing with complex problems. Specifically, we argue that managers choose nonequity partnerships to solve complex problems when relevant knowledge is not hidden and equity partnerships when this knowledge is hidden. These findings regarding complex problems are somewhat different from previous conceptualizations $[7,21]$ and provide a more solid, less contradictory hypothesizing basis for future studies.

Second, we introduce a comparative analysis of alternative OI modes by discussing the benefits of communication and knowledge exchange [7] and breadth of external partners [20,31], as well as transaction [46] and set-up costs [13, 27] for each mode. We argue that the omission of any of those factors - benefits or costs - may lead to an incomplete, distorted analysis of the appropriateness and fit of OI modes for different projects. For example, in the absence of set-up costs, equity partnerships would seem superior to all other OI modes (high communication and knowledge exchange benefits, low transaction costs) and might appear as a "silver bullet" for any type of problem. In reality however, managers seem to use equity partnerships only as a last resort, most likely due to their high set-up costs. By discussing OI mode selection patterns as driven by 
both problem attributes and the cost-benefit profiles of each mode, we provide a well-rounded, realistic framework for the analysis of OI governance.

Third, our findings show that the two key problem attributes, i.e., complexity and knowledge hiddenness, have both individual and combined effects on OI mode selection. This contributes to the OI literature, in general, and the OI governance literature in particular, by highlighting the importance of considering the interaction effect between problem attributes. Thus, future research should not simply study the effect of each problem attribute separately, but should also consider their joint effect, to understand fully the role of problem attributes in OI mode selection.

Fourth, our findings regarding how managers tackle complex problems can enhance understanding and conceptualization of the relationship between problem complexity and decomposability, in an OI context. Prior conceptual work [7] argued that decomposing complex problems into sub-problems can lead to projectthreatening integration difficulties, due to intricate interdependencies between the relevant knowledge sets. Yet, in real life, managers and firms frequently decompose highly complex problems into sub-systems (see our survey results and the Boeing 787 Dreamliner illustration) which they assign to strategic partners possessing the relevant knowledge sets. We contribute to this perspective by showing that the focal or flagship firm must often engage in extensive (system) integration work when decomposing a complex problem, to ensure that the final solution addresses all the interconnections and interdependences between the elements of the complex problem. Managers appear to value the benefits of decomposition and OI (e.g., reduced development costs and lead times, access to external complementary capabilities, etc.) despite the high system integration costs inherent in decomposing a complex problem. Only when the knowledge sets relevant to a complex problem do not exist or are hidden do managers fail to decompose complex problems, preferring to develop integrated solutions within the confines of more hierarchical OI governance modes, such as equity partnerships. Therefore, our study indicates that, in the context of OI, problem decomposability does not depend exclusively on problem complexity. Instead, we argue that problem decomposability is a function of both complexity and knowledge hiddenness. Put differently, we propose that a complex problem is nondecomposable only when 
the relevant interdependent knowledge sets are hidden from the focal firm. Our findings re-conceptualize the relationship between complexity and decomposability, aligning innovation literature with managerial practice, which often involves outsourcing sub-system design and development even for the most complex projects (albeit subject to subsequent integration efforts).

\subsection{Managerial Implications}

Our study has clear and immediate managerial implications. It provides an empirically supported decision framework for managers who are considering which OI mode to choose. While we do not claim to provide a panacea for all firms and all OI projects, we provide a potential roadmap for OI project governance (Figure 1) that can inform early stage decisions, which may in turn have important implications for the project performance and resource allocation in later stages. Broadly, the $2 \times 2$ matrix in Figure 1 can serve a compass for managerial decision-making in OI projects. However, we also dig deeper into the micro-foundations of OI, providing a more comprehensive analytical framework for managers to select their OI modes and organize OI activities based on the interplay between problem attributes and the cost-benefit profiles of various OI modes.

\section{----- INSERT FIGURE 1 ABOUT HERE -----}

Moreover, our findings can help managers decide whether to decompose complex problems into different subproblems to which they can find solutions in collaboration with external partners. Our findings show that such decomposition does not only depend on problem complexity. Instead, problem complexity and knowledge hiddenness jointly drive problem decomposition decisions. More precisely, managers can think of complex problem decomposition only when the knowledge required for sub-problem solving exist, and they know which partners have the knowledge required to help them with their innovation projects.

\subsection{Limitations and Future Research}

Our paper provides rare project-level insights into the OI process. It is the first empirical study to explore how managers can use different OI modes to address different types of problems. Although a step in the right direction, our endeavor is not without limitations. First, our theoretical framework integrates two views in the OI governance literature, namely the problem-solving view [7, 29] and the transaction cost view 
[30]. We make a first attempt to incorporate the cost view into the problem-solving discussion. However, we are well aware that problem solving may entail additional costs (e.g. search costs, knowledge integration cost, etc.). We hope that future research will take up this challenge to revisit the assumptions of the frameworks used in this paper - the problem-solving and transaction costs views - and develop a more comprehensive theory.

Second, our empirical exploration shows that project attributes play a critical role in OI mode selection. However, project attributes and firm level-characteristics may affect OI mode selection jointly. Thus, future studies could further explore how firm-level factors influence the relationship between project attributes and OI mode selection (i.e., cross-level interaction between project and firm level factors).

Third, even though the two problem attributes studied in this paper are important drivers of OI mode selection [7, 21, 37], exploring other relevant problem attributes (e.g., strategic importance of projects or novelty of needed knowledge) would be a fruitful direction for future research.

Fourth, we decided to exclude innovation communities (e.g., $[7,21])$ from our study. Our decision was motivated by definitional ambiguities and conceptual overlaps between innovation communities and other OI modes such as OI platforms and non-equity partnerships. In addition, the costs entailed and benefits provided by innovation communities can vary substantially from one case to another, making it very difficult to categorize innovation communities in our cost-benefit analytical framework. Nevertheless, future empirical studies may want to account for innovation communities as a valid OI mode.

Fifth, as we collected the data from a single respondent in each project, this research is vulnerable to common method variance (CMV) [81]. We proximally separated the measures related to OI modes and the two project attributes in the survey, reducing the likelihood of respondents predicting the relationship between the variables [82]. Moreover, most of the measures were objective, reducing the probability of variable overestimation or underestimation. Although, the CMV effect is controlled by these initiatives, future research should take a multi-source approach (e.g., collecting data for OI modes and project attributes from two respondents or from different data sources) to circumvent the CMV problem entirely. 


\section{REFERENCES}

[1] H. Chesbrough and S. Brunswicker, "A Fad or a Phenomenon?: The Adoption of Open Innovation Practices in Large Firms," Research-Technology Management, vol. 57, no. 2, pp. 16-25, 2014.

[2] Y.-C. Wu, B.-W. Lin, and C.-J. Chen, "How do internal openness and external openness affect innovation capabilities and firm performance?," IEEE Transactions on Engineering Management, vol. 60, no. 4, pp. 704-716, 2013.

[3] Q. Chen and Z. Liu, "How does openness to innovation drive organizational ambidexterity? The mediating role of organizational learning goal orientation," IEEE Transactions on Engineering Management, vol. 66, no. 2, pp. 156-169, 2018.

[4] S. Brunswicker and H. Chesbrough, "The Adoption of Open Innovation in Large Firms: Practices, Measures, and Risks A survey of large firms examines how firms approach open innovation strategically and manage knowledge flows at the project level," Research-Technology Management, vol. 61 , no. 1 , pp. $35-45,2018$.

[5] M. Bagherzadeh, S. Markovic, J. Cheng, and W. Vanhaverbeke, "How Does Outside-In Open Innovation Influence Innovation Performance? Analyzing the Mediating Roles of Knowledge Sharing and Innovation Strategy," IEEE Transactions on Engineering Management, 2019. DOI: 10.1109/TEM.2018.2889538.

[6] M. L. Flor, M. J. Oltra-Mestre, and E. L. Sanjurjo, "An Analysis of Open Innovation Strategies in Firms in Low and Medium Technology Industries," IEEE Transactions on Engineering Management, 2019. DOI: 10.1109/TEM.2019.2911253.

[7] T. Felin and T. R. Zenger, "Closed or open innovation? Problem solving and the governance choice," Research Policy, vol. 43, no. 5, pp. 914-925, 2014.

[8] V. van de Vrande, W. Vanhaverbeke, and G. Duysters, "External technology sourcing: The effect of uncertainty on governance mode choice," Journal of Business Venturing, vol. 24, no. 1, pp. 62-80, 2009.

[9] R. Veugelers and B. Cassiman, "Make and buy in innovation strategies: evidence from Belgian manufacturing firms," Research Policy, vol. 28, no. 1, pp. 63-80, 1999. 
[10] I. Geyskens, J.-B. E. Steenkamp, and N. Kumar, "Make, buy, or ally: A transaction cost theory metaanalysis," Academy of Management Journal, vol. 49, no. 3, pp. 519-543, 2006.

[11] L. Huston and N. Sakkab, "Connect and develop," Harvard Business Review, vol. 84, no. 3, pp. 58-66, 2006.

[12] S. Brunswicker, M. Bagherzadeh, A. Lamb, R. Narsalay, and Y. Jing, "Managing Open Innovation Projects with Impact," Whitepaper Series, July. SSRN. https://ssrn.com/abstract=2821203, 2016.

[13] A. Gurca and M. Ravishankar, "A bricolage perspective on technological innovation in emerging markets," IEEE Transactions on Engineering Management, vol. 63, no. 1, pp. 53-66, 2016.

[14] S. White, "Cooperation Costs, Governance Choice and Alliance Evolution*," Journal of Management Studies, vol. 42, no. 7, pp. 1383-1412, 2005.

[15] P. K. Lawrence and D. W. Thornton, Deep stall: the turbulent story of Boeing commercial airplanes: Routledge, 2017.

[16] G. Norris and M. Wagner, Boeing 787 dreamliner: Zenith Press, 2009.

[17] J. West, W. Vanhaverbeke, and H. Chesbrough, "Open innovation: a research agenda," Open innovation: Researching a new paradigm, pp. 285-307, 2006.

[18] D. Antons, R. Kleer, and T. O. Salge, "Mapping the Topic landscape of JPIM, 1984-2013: In search of hidden structures and development trajectories," Journal of Product Innovation Management, vol. 33, no. 6 , pp. 726-749, 2016.

[19] K. Randhawa, R. Wilden, and J. Hohberger, "A bibliometric review of open innovation: Setting a research agenda," Journal of Product Innovation Management, vol. 33, no. 6, pp. 750-772, 2016.

[20] A. Afuah and C. L. Tucci, "Crowdsourcing as a solution to distant search," Academy of Management Review, vol. 37, no. 3, pp. 355-375, 2012.

[21] G. P. Pisano and R. Verganti, "Which kind of collaboration is right for you," Harvard Business Review, vol. 86 , no. 12 , pp. $78-86,2008$.

[22] J. West, A. Salter, W. Vanhaverbeke, and H. Chesbrough, "Open innovation: The next decade," Research Policy, vol. 43, no. 5, pp. 805-811, 2014. 
[23] H. Simon, "The architecture of complexity," Proceedings of the American Philosophical Society, vol. 106, no. 6, pp. 467-482, 1962.

[24] R. Fernandes and H. A. Simon, "A study of how individuals solve complex and ill-structured problems," Policy Sciences, vol. 32, no. 3, pp. 225-245, 1999.

[25] A. Malhotra and A. Majchrzak, "Managing crowds in innovation challenges," California Management Review, vol. 56, no. 4, pp. 103-123, 2014.

[26] J. Howells, "Intermediation and the role of intermediaries in innovation," Research Policy, vol. 35, no. 5, pp. 715-728, 2006.

[27] M. G. Colombo, "Alliance form: A test of the contractual and competence perspectives," Strategic Management Journal, vol. 24, no. 12, pp. 1209-1229, 2003.

[28] J. H. Dyer, "Effective interfirm collaboration: how firms minimize transaction costs and maximize transaction value," Strategic Management Journal, vol. 18, no. 7, pp. 535-556, 1997.

[29] J. A. Nickerson and T. R. Zenger, "A knowledge-based theory of the firm-The problem-solving perspective," Organization Science, vol. 15, no. 6, pp. 617-632, 2004.

[30] O. E. Williamson, "Comparative economic organization: The analysis of discrete structural alternatives," Administrative Science Quarterly, pp. 269-296, 1991.

[31] S. Markovic and M. Bagherzadeh, "How does breadth of external stakeholder co-creation influence innovation performance? Analyzing the mediating roles of knowledge sharing and product innovation," Journal of Business Research, vol. 88, pp. 173-186, 2018.

[32] H. Chen, S. Zeng, B. Yu, and H. Xue, "Complementarity in Open Innovation and Corporate Strategy: The Moderating Effect of Ownership and Location Strategies," IEEE Transactions on Engineering Management, 2019. DOI: 10.1109/TEM.2018.2889804.

[33] J. West and M. Bogers, "Open innovation: current status and research opportunities," Innovation, vol. 19, no. 1, pp. 43-50, 2017.

[34] J. Du, B. Leten, and W. Vanhaverbeke, "Managing open innovation projects with science-based and market-based partners," Research Policy, vol. 43, no. 5, pp. 828-840, 2014. 
[35] M. Bagherzadeh Niri, "Governance of Inter-Organizational Collaborations When Engaged in Open Innovation," PhD dissertation Published Thesis, Universitat Ramon Llull, 2016.

[36] N. Kim, D. J. Kim, and S. Lee, "Antecedents of open innovation at the project level: empirical analysis of Korean firms," R\&D Management, vol. 45, no. 5, pp. 411-439, 2015.

[37] B. Heiman and J. A. Nickerson, "Empirical evidence regarding the tension between knowledge sharing and knowledge expropriation in collaborations," Managerial and Decision Economics, vol. 25, no. 67, pp. 401-420, 2004.

[38] G. Gavetti and D. Levinthal, "Looking forward and looking backward: Cognitive and experiential search," Administrative Science Quarterly, vol. 45, no. 1, pp. 113-137, 2000.

[39] C. S. Tang, J. D. Zimmerman, and J. I. Nelson, "Managing new product development and supply chain risks: The Boeing 787 case," Supply Chain Forum: An International Journal, vol. 10, no. 2, pp. 74-86, 2009.

[40] H. Chesbrough, Open innovation: The new imperative for creating and profiting from technology: Harvard Business Press, 2003.

[41] A. Majchrzak, S. L. Jarvenpaa, and M. Bagherzadeh, "A review of interorganizational collaboration dynamics," Journal of Management, vol. 41, no. 5, pp. 1338-1360, 2015.

[42] M. D. Santoro and J. P. McGill, "The effect of uncertainty and asset co-specialization on governance in biotechnology alliances," Strategic Management Journal, vol. 26, no. 13, pp. 1261-1269, 2005.

[43] L. Ardito, A. M. Petruzzelli, and V. Albino, "The Influence of Alliance Ambidexterity on Innovation Performance and the Moderating Role of Firm Age," IEEE Transactions on Engineering Management, 2019. DOI: 10.1109/TEM.2019.2902069.

[44] S. Makino, C. M. Chan, T. Isobe, and P. W. Beamish, "Intended and unintended termination of international joint ventures," Strategic Management Journal, vol. 28, no. 11, pp. 1113-1132, 2007.

[45] J. Li-Ying and Y. Wang, "Find Them Home or Abroad? The Relative Contribution of International Technology In-licensing to "Indigenous Innovation" in China," Long Range Planning, vol. 48, no. 3, pp. 123-134, 2015. 
[46] R. Gulati and H. Singh, "The architecture of cooperation: Managing coordination costs and appropriation concerns in strategic alliances," Administrative Science Quarterly, pp. 781-814, 1998.

[47] P. W. Vlaar, F. A. Van Den Bosch, and H. W. Volberda, "Towards a dialectic perspective on formalization in interorganizational relationships: How alliance managers capitalize on the duality inherent in contracts, rules and procedures," Organization Studies, vol. 28, no. 4, pp. 437-466, 2007.

[48] D. Faems, M. Janssens, and B. Van Looy, "Managing the Co-operation-Competition Dilemma in R\&D Alliances: A Multiple Case Study in the Advanced Materials Industry," Creativity and Innovation Management, vol. 19, no. 1, pp. 3-22, 2010.

[49] M. B. Niri and S. Brunswicker, "Joint Exploration with the Enemy-Revealing Needed?," Proceedings of the 1st ISPIM Americas innovation forum. Montreal, Canada (2014), 2014.

[50] M. Bogers, "The open innovation paradox: knowledge sharing and protection in R\&D collaborations," European Journal of Innovation Management, vol. 14, no. 1, pp. 93-117, 2011.

[51] K. Laursen and A. Salter, "Open for innovation: the role of openness in explaining innovation performance among UK manufacturing firms," Strategic Management Journal, vol. 27, no. 2, pp. 131$150,2006$.

[52] L. Dahlander and D. M. Gann, "How open is innovation?," Research Policy, vol. 39, no. 6, pp. 699709, 2010.

[53] M. J. Leiblein and J. T. Macher, "The problem solving perspective: A strategic approach to understanding environment and organization," Advances in Strategic Management, vol. 26, pp. 97-120, 2009.

[54] H. Lopez-Vega, F. Tell, and W. Vanhaverbeke, "Where and how to search? Search paths in open innovation," Research Policy, vol. 45, no. 1, pp. 125-136, 2016.

[55] L. B. Jeppesen and K. R. Lakhani, "Marginality and problem-solving effectiveness in broadcast search," Organization Science, vol. 21, no. 5, pp. 1016-1033, 2010.

[56] O. A. Acar, "Motivations and solution appropriateness in crowdsourcing challenges for innovation," Research Policy, vol. 48, no. 8, p. 103716, 2019. 
[57] K. J. Boudreau and K. R. Lakhani, "Using the crowd as an innovation partner," Harvard Business Review, vol. 91, no. 4, pp. 60-9, 140, 2013.

[58] H. Berends, E. Van Burg, and E. M. Van Raaij, "Contacts and contracts: Cross-level network dynamics in the development of an aircraft material," Organization Science, vol. 22, no. 2, pp. 940-960, 2011.

[59] S. Balakrishnan and M. P. Koza, "Information asymmetry, adverse selection and joint-ventures: Theory and evidence," Journal of Economic Behavior \& Organization, vol. 20, no. 1, pp. 99-117, 1993.

[60] H. Mjoen and S. Tallman, "Control and performance in international joint ventures," Organization Science, vol. 8, no. 3, pp. 257-274, 1997.

[61] M. Bagherzadeh and S. Brunswicker, "The Role of Behavioral Control," in Decision Making in Behavioral Strategy, ed: Das, T. K., Information Age Publishing (IAP), 2016, pp. 99-119.

[62] T. Felin, N. J. Foss, and R. E. Ployhart, "The microfoundations movement in strategy and organization theory," The Academy of Management Annals, vol. 9, no. 1, pp. 575-632, 2015.

[63] J. Tan, Y. Shao, and W. Li, "To be different, or to be the same? An exploratory study of isomorphism in the cluster," Journal of Business Venturing, vol. 28, no. 1, pp. 83-97, 2013.

[64] E. Mollick, "The dynamics of crowdfunding: An exploratory study," Journal of Business Venturing, vol. 29 , no. 1 , pp. 1-16, 2014.

[65] N. Kumar, L. W. Stern, and J. C. Anderson, "Conducting interorganizational research using key informants," Academy of Management Journal, vol. 36, no. 6, pp. 1633-1651, 1993.

[66] J. L. Schafer and J. W. Graham, "Missing data: our view of the state of the art," Psychological Methods, vol. 7, no. 2, pp. 147-177, 2002.

[67] J. C. Nunnally and I. H. Bernstein, Psychometric Theory (3rd ed.). New York, NY, USA: McGrawHill, Inc., 1994.

[68] J. F. Hair, R. E. Anderson, R. L. Tatham, and W. C. Black, "Multivariate analysis," Englewood: Prentice Hall International, 1998.

[69] A. Von Eye, Configural frequency analysis: Methods, models, and applications: Psychology Press, 2003. 
[70] G. Punj and D. W. Stewart, "Cluster analysis in marketing research: review and suggestions for application," Journal of Marketing Research, vol. 20, no. 2, pp. 134-148, 1983.

[71] D. J. Ketchen and C. L. Shook, "The application of cluster analysis in strategic management research: an analysis and critique," Strategic Management Journal, vol. 17, no. 6, pp. 441-458, 1996.

[72] S. Borrás and S. J. Haakonsson, "European Firms’’ Reasons for Taking Part in Global Innovation Networks," 2010.

[73] D. Smith, Exploring innovation: McGraw-Hill Higher Education, 2015.

[74] T. Fujimoto, "Architecture-based comparative advantage - a design information view of manufacturing," Evolutionary and Institutional Economics Review, vol. 4, no. 1, pp. 55-112, 2007.

[75] D. Sweeney, "Extreme ultraviolet lithography: Imagining the Future. ," Science and Technology Review, available online at: https://str.llnl.gov/str/Sween.html, 1999.

[76] G. Müller-Seitz and J. Sydow, "Maneuvering between networks to lead-A longitudinal case study in the semiconductor industry," Long Range Planning, vol. 45, no. 2/3, pp. 105-135, 2012.

[77] J. Dorsch, "ASML MAY JOIN EUV EFFORT," ELECTRONIC NEWS, vol. 44, pp. 2-3, 1998.

[78] J. Chappell, "EUV LLC Says Technology is Ready," Electronic News, vol. 47, no. 13, pp. 30-30, 2001.

[79] J. Morris, "Intel inches closer to EUV lithography," Available online at: http://www.zdnet.com/article/iedm-2017-intel-inches-closer-to-euv-lithography/, 2017.

[80] P. Dunn, "Intel is prime mover to fund EUV litho project," Solid State Technology vol. 40, no. 4, p. 36, 1997.

[81] P. M. Podsakoff and D. W. Organ, "Self-reports in organizational research: Problems and prospects," Journal of Management, vol. 12, no. 4, pp. 531-544, 1986.

[82] P. M. Podsakoff, S. B. MacKenzie, J.-Y. Lee, and N. P. Podsakoff, "Common method biases in behavioral research: a critical review of the literature and recommended remedies," Journal of Applied Psychology, vol. 88, no. 5, p. 879, 2003. 
Table 1. Comparative analysis of the cost-benefit profiles for OI modes

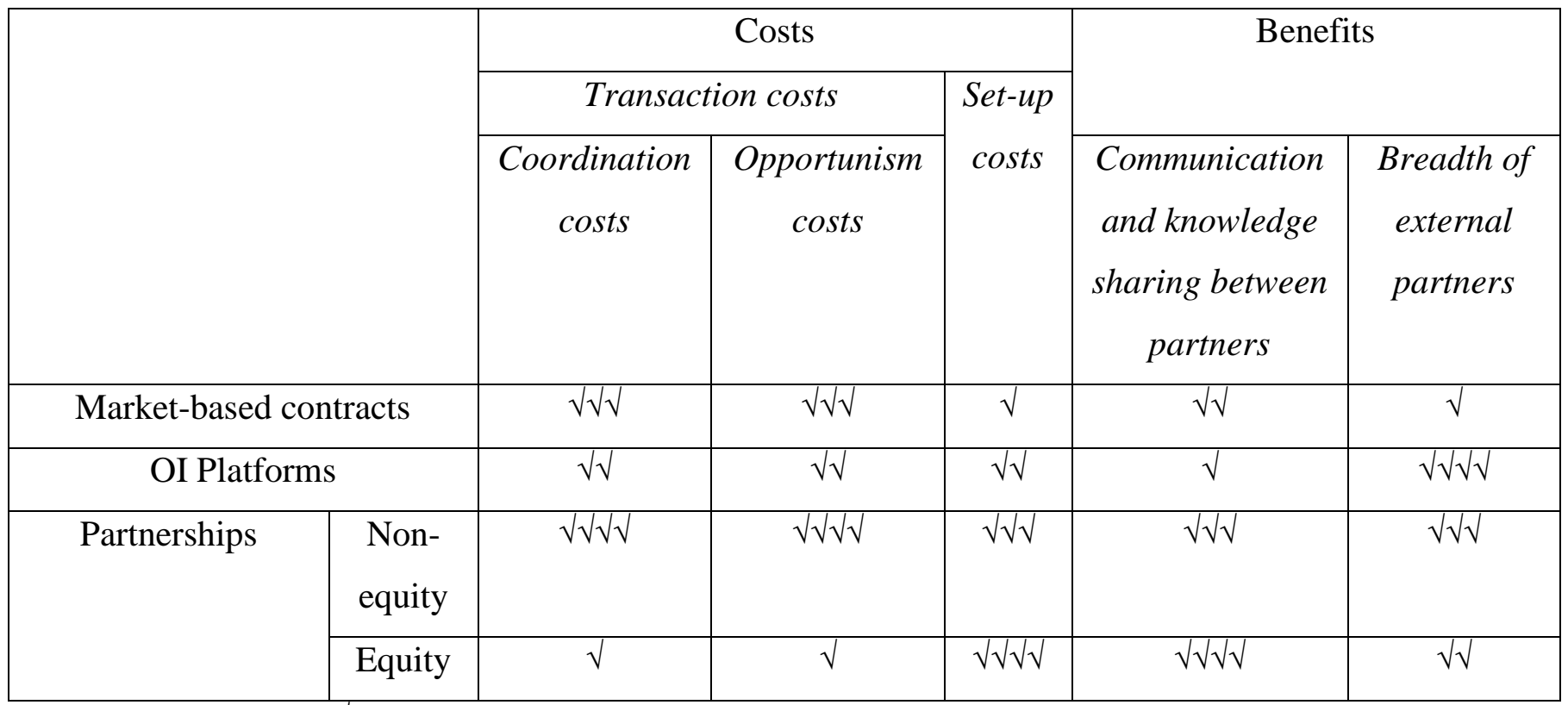

Note. The number of " $\sqrt{ }$ " (i.e., 1 to 4 ) suggests the size and intensity of costs and benefits.

Table 2. Four types of OI projects based on the two problem attributes

\begin{tabular}{|l|c|c|c|c|c|c|}
\hline $\begin{array}{l}\text { Problem } \\
\text { Attributes }\end{array}$ & $\begin{array}{c}\text { Project type 1: } \\
\text { Simple } \\
\text { problems/ } \\
\text { Knowledge is } \\
\text { not hidden } \\
(\mathrm{n}=19)\end{array}$ & $\begin{array}{c}\text { Project type 2: } \\
\text { Simple } \\
\text { problems/ } \\
\text { Knowledge is } \\
\text { hidden } \\
(\mathrm{n}=15)\end{array}$ & $\begin{array}{c}\text { Project type 3: } \\
\text { Complex } \\
\text { problems/ } \\
\text { Knowledge is } \\
\text { not hidden } \\
(\mathrm{n}=29)\end{array}$ & $\begin{array}{c}\text { Project type 4: } \\
\text { Complex } \\
\text { problems/ } \\
\text { Knowledge is } \\
\text { hidden } \\
(\mathrm{n}=22)\end{array}$ & $\begin{array}{c}\text { ANOVA } \\
\text { F-value } \\
(\mathrm{df}=3)\end{array}$ & $\begin{array}{c}\text { T-test } \\
\text { t-value }\end{array}$ \\
\hline Complexity & 3.53 & 3.43 & 6.09 & 6.00 & $74.422^{*}$ & $\begin{array}{c}3,4> \\
1,2^{*}\end{array}$ \\
\hline Knowledge & 2.11 & 5.47 & 2.03 & 5.41 & $123.710^{*}$ & $\begin{array}{c}2,4> \\
1,3^{*}\end{array}$ \\
\hline
\end{tabular}

Note: $\mathrm{n}=$ Number of projects in each project type; $* \mathrm{p}<0.001$ 
Table 3. Four clusters of OI projects based on OI Modes

\begin{tabular}{|l|c|c|c|c|}
\hline \multicolumn{1}{|c|}{ OI Modes } & $\begin{array}{c}\text { Cluster 1: } \\
\text { Market-based } \\
\text { contracts } \\
(\mathrm{n}=28)\end{array}$ & $\begin{array}{c}\text { Cluster 2: } \\
\text { OI platforms } \\
(\mathrm{n}=18)\end{array}$ & $\begin{array}{c}\text { Cluster 3: } \\
\text { Non-equity } \\
\text { partnerships } \\
(\mathrm{n}=25)\end{array}$ & $\begin{array}{c}\text { Cluster 4: } \\
\text { Equity partnerships } \\
(\mathrm{n}=14)\end{array}$ \\
\hline Market-based contracts & Yes (100\%) & Yes (61.1\%) & Yes (60\%) & Yes (85.7\%) \\
\hline OI platforms & No (100\%) & Yes (100\%) & No (100\%) & No (71.4\%) \\
\hline Non-equity partnerships & No (100\%) & No (55.6\%) & Yes $(100 \%)$ & No (100\%) \\
\hline Equity partnerships & No (100\%) & No (94.4\%) & No $(100 \%)$ & Yes $(100 \%)$ \\
\hline
\end{tabular}

Note: Yes $=$ Adopted; No $=$ Not adopted; $\mathrm{n}=$ Number of projects in each cluster

Table 4. Cross-tabulation of four types of projects and four clusters of OI modes

\begin{tabular}{|c|c|c|c|c|c|}
\hline & \multicolumn{4}{|c|}{ Clusters of OI modes } \\
\hline & & $\begin{array}{c}\text { Cluster } 1 \\
\text { Market-based } \\
\text { contracts }\end{array}$ & $\begin{array}{c}\text { Cluster } 2 \\
\text { OI platforms }\end{array}$ & $\begin{array}{c}\text { Cluster } 3 \\
\text { Non-equity } \\
\text { partnerships }\end{array}$ & $\begin{array}{c}\text { Cluster } 4 \\
\text { Equity } \\
\text { partnerships }\end{array}$ \\
\hline \multirow{4}{*}{$\begin{array}{l}\text { Types of } \\
\text { projects }\end{array}$} & $\begin{array}{c}\text { Project type 1 } \\
\text { (Simple problems/ } \\
\text { Knowledge is not } \\
\text { hidden) }\end{array}$ & $\begin{array}{l}\text { Obs. } 8^{11} \\
\text { Exp. } 6.259 \\
(0.288)\end{array}$ & $\begin{array}{l}\text { Obs. } 6^{\underline{12}} \\
\text { Exp. } 4.024 \\
(0.215)\end{array}$ & $\begin{array}{l}\text { Obs. } 2^{\underline{13}} \\
\text { Exp. } 5.588 \\
(\mathbf{0 . 0 7 6 )}\end{array}$ & $\begin{array}{l}\text { Obs. } 3^{\underline{14}} \\
\text { Exp. } 3.129 \\
(0.618)\end{array}$ \\
\hline & $\begin{array}{c}\text { Project type 2 } \\
\text { (Simple problems/ } \\
\text { Knowledge is } \\
\text { hidden) }\end{array}$ & $\begin{array}{l}\text { Obs. } 4^{21} \\
\text { Exp. } 4.941 \\
(0.446) \\
\end{array}$ & $\begin{array}{l}\text { Obs. } 6 \\
\text { Exp. } 3.176 \\
(\mathbf{0 . 0 9 9 )} \\
\end{array}$ & $\begin{array}{l}\text { Obs. } 4 \underline{23} \\
\text { Exp. } 4.412 \\
(0.547) \\
\end{array}$ & $\begin{array}{l}\text { Obs. } 1 \\
\text { Exp. } 2.471 \\
(0.289) \\
\end{array}$ \\
\hline & $\begin{array}{c}\text { Project type } 3 \\
\text { (Complex problems/ } \\
\text { Knowledge is not } \\
\text { hidden) }\end{array}$ & $\begin{array}{l}\text { Obs. } 9^{\underline{31}} \\
\text { Exp. } 9.553 \\
(0.511)\end{array}$ & $\begin{array}{l}\text { Obs. } 2 \underline{32} \\
\text { Exp. } 6.141 \\
(\mathbf{0 . 0 5})\end{array}$ & $\begin{array}{l}\quad \underline{33} \\
\text { Obs. } 15 \\
\text { Exp. } 8.529 \\
(\mathbf{0 . 0 2 2})\end{array}$ & $\begin{array}{l}\text { Obs. } 3^{\underline{34}} \\
\text { Exp. } 4.776 \\
(0.29)\end{array}$ \\
\hline & $\begin{array}{c}\text { Project type } 4 \\
\text { (Complex problems/ } \\
\text { Knowledge is } \\
\text { hidden) }\end{array}$ & $\begin{array}{l}\text { Obs. } 7^{\underline{41}} \\
\text { Exp. } 7.247 \\
(0.56)\end{array}$ & $\begin{array}{l}\text { Obs. } 4 \\
\text { Exp. } 4.659 \\
(0.499)\end{array}$ & $\begin{array}{l}\text { Obs. } 4^{\underline{43}} \\
\text { Exp. } 6.471 \\
(0.216)\end{array}$ & $\begin{array}{l}\text { Obs. }{ }^{\underline{44}} \\
\text { Exp. } 3.624 \\
(\mathbf{0 . 0 7 1 )}\end{array}$ \\
\hline Chi-square & & & $\mathrm{df}=9, \mathrm{p}$-value $=$ & & \\
\hline
\end{tabular}

Note: Underlined number $=$ Cell index; Obs. $=$ Observed frequency of projects; Exp. $=$ Expected frequency of projects; $\mathrm{df}=$ degree of freedom; Binominal test $\mathrm{p}$-values are in parentheses; Bold numbers indicate the significant difference in each cell. 
Figure 1. Typology of four project types and preferred OI modes

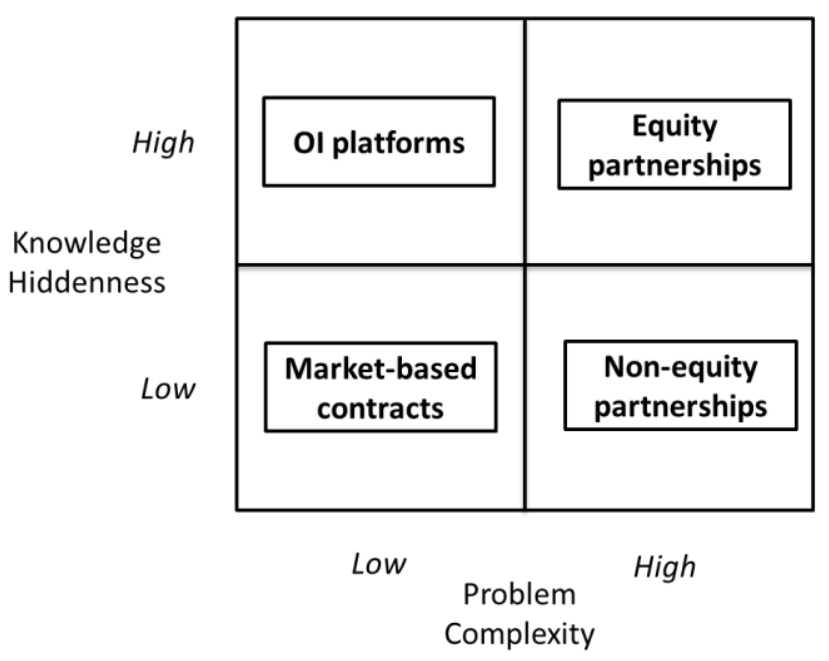

